\title{
AGAMÉMNON E CLITEMNESTRA NA ESCOLA: OS CLÁSSICOS COMO TEMA ESTRUTURANTE DE THE BROWNING VERSION*
}

\author{
Nuno Simões Rodrigues \\ CH-ULisboa/CEC-ULisboa/CECH-UC - Universidade de Lisboa \\ nonnius@fl.ul.pt \\ orcid.org/0000-0001-6109-4096
}

\section{RESUMEN}

Este texto analisa a forma como o dramaturgo inglês Terence Rattigan recorre à tragédia Agamémnon de Ésquilo para dar corpo ao texto dramático de sua autoria, The Browning Version (1946). A análise que se propóe contempla ainda a forma como os elementos da cultura grega foram incluídos e adaptados nas versóes cinematográficas que Anthony Asquith e Mike Figgis fizeram da peça de Rattigan em 1951 e 1994, respectivamente.

Palabras Clave: Agamémnon, Clitemnestra, Ésquilo, Terence Rattigan, Cinema.

\author{
AGAMEMNON AND CLYTEMNESTRA AT SCHOOL: \\ THE CLASSICS AS A STRUCTURING MOTIF OF \\ THE BROWNING VERSION
}

\section{ABSTRACT}

This essay analyzes the way in which the English playwright Terence Rattigan uses the tragedy Agamemnon by Aeschylus to structure the dramatic text of his authorship, The Browning Version (1946). The proposed analysis also takes into consideration how the elements of Greek culture were included and adapted in the film versions that Anthony Asquith and Mike Figgis made of Rattigan's play in 1951 and 1994, respectively.

KeY Words: Agamemnon, Clytemnestra, Aeschylus, Terence Rattigan, Cinema.

Este estudo insere-se numa problemática mais ampla: a da recepção dos temas clássicos na cultura contemporânea, mais concretamente no cinema ${ }^{1}$. Com efeito, a Antiguidade Clássica e as temáticas a ela associadas nunca deixaram de estar presentes nas fórmulas culturais que o Ocidente tem conhecido ao longo da sua história, até aos dias de hoje. O cinema, como expressão privilegiada da cultura, umas vezes popular, outras erudita, não é excepção a essa regra. O caso que aqui apresentamos é disso exemplo. Mas The Browning Version tem ainda a particularidade de traduzir dois tipos de recepção: aquela que se verifica no cinema, claro; mas também aquela 
que se tem reconhecido na literatura dramática, desde que esta floreceu na própria Antiguidade. Com efeito, as versōes cinematográficas aqui estudadas derivam de um medium cultural intermédio, entre o tema antigo e o cinema, que é o teatro contemporâneo. Por conseguinte, também essa questão será levada em conta.

O filme The Browning Version, realizado em 1994 por Mike Figgis, é uma adaptação, feita pelo guionista e também dramaturgo Ronald Harwood, da peça homónima que Terence Rattigan escreveu em 1946 e levou à cena londrina em $1948^{2}$. Apesar da intervenção de Harwood, porém, o filme de Figgis assenta em grande parte numa outra adaptação cinematográfica de 1951, da autoria de Anthony Asquith, mas com argumento do próprio Rattigan. Por conseguinte, o essencial das versões fílmicas da peça, bem como as opçōes dos respectivos argumentos, radicam em grande parte no autor do texto original.

Centrando-se na figura de um professor de filologia clássica de uma escola pública inglesa, um oxoniense de nome Andrew Crocker-Harris, tanto a peça de teatro como os filmes dela derivados assentam em hipotextos, apesar das evidentes e reconhecidas reminiscências auto-biográficas do autor na narrativa. Exemplo disso é o facto de ele próprio ter estudado línguas clássicas e ter sido aluno em Harrow, uma escola em que havia um professor de grego e latim chamado J. W. Coke-Norris, que se aposentou enquanto Rattigan lá estudava ${ }^{3}$. Evidentemente, o nome desse professor ressoa no da personagem central de The Browning Version: Andrew Crocker_Harris.

Dos textos de base a que aludimos, destaca-se Goodbye, $M r$. Chips, romance de James Hilton, publicado em 1934, cujo argumento gira em torno de um medíocre docente de línguas clássicas, Mr. Chipping, todavia conhecido pela sua rigorosa disciplina e que conseguirá o afecto dos seus alunos na sequência de diversas vicissitudes, entre as quais o facto de se ter casado com uma jovem e atraente mulher que

* Este estudo é financiado por Fundos Nacionais através da FCT - Fundação para a Ciência e a Tecnologia, I.P., no âmbito dos projectos UID/ELT/00019/2013 do Centro de Estudos Clássicos da Universidade de Lisboa, UID/ELT/00196/2013 do Centro de Estudos Clássicos e Humanísticos da Universidade de Coimbra e UID/HIS/04311/2013 do Centro de História da Universidade de Lisboa.

${ }^{1}$ Esta é uma problemática que conhece já uma bibliografia em quantidade e, sobretudo, qualidade significativas. A título de mero exemplo, citamos Martínez Hernández, 2012, e o clássico de Solomon, 2001.

${ }^{2}$ The Browning Version é uma peça de teatro da autoria do dramaturgo britânico Terence Rattigan (1911-1977), sendo mesmo considerada por alguns críticos como a melhor das obras desse autor. A peça estreou em Londres, a seguir à II Grande Guerra, em 1948. Originalmente, o texto foi concebido para ser apresentado juntamente com outra composição a funcionar como segunda parte da encenação. Juntas, The Browning Versione Harlequinade, a outra peça, foram intituladas Playbill. The Browning Version desenrola-se numa escola pública inglesa para rapazes e tem como figura central um professor de Clássicas prestes a aposentar-se. Sobre a peça de Rattigan, vide Bertolini, 2016.

${ }^{3}$ Patterson, 2009: 15; Palaima, 2002: 200. 
conquista toda a comunidade estudantil. Goodbye, Mr. Chips acabou por ser adaptado ao cinema por duas vezes, em 1939 e em 1969, tendo a primeira adaptação sido agraciada com o óscar para o melhor actor desse ano, Robert Donat, e a segunda transformado o argumento de base num musical. O uso de Goodbye, Mr. Chips, contudo, é essencialmente subliminar, apesar de Rattigan atribuir à personagem Millie Crocker-Harris, quer no texto da peça quer na versão cinematográfica de 1951, uma alusão directa e explícita a esse romance/filme: trata-se do momento em que a mulher do professor revela o seu descontentamento pelo facto de o marido não vir a ser contemplado com qualquer pensão pela sua aposentação do serviço na escola .

O outro texto na base de The Browning Version é bem mais explícito. Referimo-nos, naturalmente, ao Agamémnon de Ésquilo, tragédia grega que está por detrás do próprio título da peça de Rattigan e dos filmes dela derivados 5 . Com efeito, «The Browning Version» é uma referência à tradução que o poeta e dramaturgo inglês Robert Browning fez da peça de Ésquilo em 1877, em plena época vitoriana, portanto. Mas os sinais da presença do Agamémnon esquiliano, que Crocker-Harris considera "perhaps the greatest play ever written", são também evidentes ao longo da peça e das respectivas adaptaçôes ao cinema, funcionando inclusive como seu elemento estruturante. Vejamos em que sentido.

Apesar de no texto dramático tudo se passar em tempo real, num único espaço (a sala de estar do apartamento de Crocker-Harris, como indica a didascália de abertura da peça), nos filmes, a acção foi expandida, de modo a obedecer às regras da expressão cinematográfica. Com efeito, se a dramaturgia trágica clássica diz, o cinema mostra. Os argumentos das adaptaçóes ao cinema de 1951 e de 1994 rompem, portanto, com a aparente pretensão de Rattigan de compor um texto de modelo clássico, como sugere a peça, de tonalidade naturalista e essencialmente psicológica, estruturada num único acto, em tempo real e num único lugar. Rattigan parece assim seguir a pretensa lei aristotélica das três unidades que, no entanto, resulta da hermenêutica renascentista e neo-clássica e de uma interpretação abusiva da Poética ${ }^{6}$. Neste sentido, o apartamento de Crocker-Harris está longe de ser o único espaço da acção fílmica de The Browning Version?. Mantém-se, contudo, a importância fulcral desse lugar, sendo que é aí que o professor parece estar mais à vontade, como se esse fosse o seu refúgio.

${ }^{4} \mathrm{O}$ texto de Rattigan, por sua vez, deverá ter inspirado E. Albee, quando este, em 1962, apresentou a peça Who's afraid of Virginia Woolf?. Vide Patterson, 2009: 20, que também considera que tanto esta peça como o filme de Mike Nichols (1966) terão influenciado a adaptação de M. Figgis. Por outro lado, em 1949, Rattigan voltaria à Antiguidade Clássica, e a Plutarco em particular, para escrever Adventure Story, peça que tem como epicentro a figura de Alexandre-o-Grande. Vide Fox, 2010.

${ }^{5}$ Sobre Ésquilo, a bibliografia é imensa. Vide e.g. Sousa e Silva (2005).

${ }^{6}$ Rodrigues, 2001: 385-408.

${ }^{7}$ Em contrapartida, o filme de Asquith conta com 16 cenários diferentes e o de Figgis tem uma acção ainda mais aberta. Vide Patterson, 2009: 78, 105. 
Partindo da ideia de que, assim como a sua relação com os alunos ${ }^{8}$, o estatuto de Crocker-Harris como professor é fundamental para o sentido da narrativa, os filmes introduzem como espaço da acção aquilo que no texto de Rattigan é meramente evocado em forma de logos: a sala de aula.

Tanto A. Asquith como M. Figgis investem particularmente neste cenário. Definido pelos elementos próprios de uma sala de aula para estudantes do lower fift $^{9}$, o ambiente é dominado pelo quadro negro, no qual podemos ler um texto em grego clássico. Neste pormenor, há que assinalar as diferenças que se verificam entre a produção de 1951 e a de 1994.

Com efeito, na versão de Asquith, o que lemos no quadro negro é um passo do Agamémnon de Ésquilo, mais concretamente os versos 414-419, uma fala atribuída ao coro: «A saudade da que foi para o outro lado do mar dá o governo da casa a um fantasma. A graça das formosas estátuas é odiosa ao esposo e a ausência duns olhos faz desaparecer todo o encanto de Afrodite» (trad. de M. O. Pulquério). Esta é uma referência a Helena. A ausência da rainha de Esparta transforma o marido dela, Menelau, num homem vazio, parecendo um fantasma.

A câmara foca o passo por diversas vezes; em particular, no momento em que Crocker-Harris (Michael Redgrave) conversa com Peter Gilbert (Ronald Howard), o jovem professor que o irá substituir no term seguinte e coordenar não apenas o departamento de Clássicas, como o de Línguas em geral. As palavras que o protagonista então profere ganham um significado ainda mais poderoso quando ouvidas com o passo esquiliano como pano de fundo. Andrew Crocker-Harris fala sobre a sua frustração ao fim de tantos anos de ensino, por não ter conseguindo converter os seus alunos à paixão que ele próprio nutre pela cultura clássica. Mas as palavras do protagonista confundem a causa pública com a sua própria vida privada, pois a frustração profissional que sente equivale metaforicamente ao falhanço pessoal, sobretudo no casamento. Andrew aponta uma «sickness of the soul» como a causa de tal desaire. Tal como Menelau é na tragédia grega, designadamente em Troianas e em Helena de Eurípides, o homem abandonado que perdeu Helena, sem honra e sem crença, eventualmente rancoroso até ${ }^{10}$, também o professor faz um auto-diagnóstico

\footnotetext{
${ }^{8}$ Juntamente com o da vivência conjugal, estes são as questôes centrais de The Browning Version.

${ }^{9}$ Sistema inglês que articulava os anos escolares com as idades dos alunos, nada tendo que ver com as capacidades académico-científicas propriamente ditas. Era, no entanto, necessário obter aprovação nos regimes «lower» para se passar para os regimes «upper». Nestes curricula, para que o aluno frequentasse as disciplinas de ciências, teria primeiro de obter aprovação no nível básico de clássicas. Este foi um dos pontos de crítica que a peça de Rattigan mereceu aquando da sua estreia, pois para muitos não parecia verosímil que um homem com a experiência académico-pedagógica de Crocker-Harris estivesse a leccionar ao lower fifth. Com efeito, o lower fifth estaria mais adequado para alguém acabado de se formar em Oxford. Vide Patterson, 2009: 15-16. A escola do filme de 1994, contudo, já não parece integrar o sistema público inglês, mas o privado, sinal de que os tempos são já de facto outros. Note-se como, entre os alunos, encontra-se, por exemplo, um jovem aristocrata africano, proveniente de uma das antigas colónias britânicas.

${ }^{10}$ Sobre esta questão, vide e.g. E. Hel. 386-566; Rocha Pereira, 1996: 14-17; Benardete, 1997: 30.
} 
da alma, confirmando a sua própria frustração, que coincide com a alcunha de que goza entre os seus alunos e que então descobre pelo colega recém-chegado: «o Himmler ${ }^{11}$ do lower fifth». Na verdade, este é apenas mais um apelido depreciativo, que se junta a outro, "The Crock»".

O efeito obtido nesta sequência é genial do ponto de vista da diegese e da narratologia cinematográfica. Mas esse artifício está também ao alcance de muito poucos. Já na versão de 1994, apesar de se manter o recurso ao grego como efeito visual, de modo a criar o ambiente subliminar clássico, as opçôes de M. Figgis foram outras, mas não menos especializadas. Nesta adaptação, o passo grego que lemos no quadro negro da sala de Crocker-Harris (Albert Finney) já não pertence ao Agamémnon de Ésquilo, mas à Odisseia. Aos primeiros versos do poema homérico ${ }^{13}$ juntam-se instruçôes didácticas, como "Translate first passage», "Construe», «Classroom exercice», e referências histórico-literárias, como «Trachiniae», «Sophocles» e «Peloponnesian». Ainda que os versos homéricos não sejam de todo desprovidos de ressonância no contexto em que são apresentados, as referências escritas no quadro da segunda película parecem não passar de um mero adereço de cena, ao contrário do simbolismo do passo esquiliano usado no primeiro filme. Esta hipótese confirma-se pelo facto de, nesta adaptação, a câmara não focar o quadro de modo nítido ou com a mesma intensidade com que o vemos na de $1951^{14}$.

Esta opção de Figgis, porém, é compensada com o foco que o realizador coloca no passo do Agamémnon que Taplow (Ben Silverstone) escolhe como epígrafe para a edição da versão Browning que compra num alfarrabista para oferecer ao professor. Andrew exibe com orgulho o presente que recebeu do aluno aos colegas e amigos que com ele estão à mesa no final do jogo de cricket, e Diana Rafferty (Maryam d'Abo), a mulher do director do departamento de ciências (Dr. Rafferty, Bruce Myers), mostra interesse em saber o que diz a dedicatória. Tom ${ }^{15}$ Gilbert (Julian Sands) começa

${ }^{11}$ A versão escrita original, de 1946, refere simplesmente «Himmler». No filme de 1951, houve já necessidade de explicitar a alusão, complementando-a com «o chefe da Gestapo». A adaptação de 1994, mais distante da guerra, alterou a referência para «Hitler». Vide Patterson, 2009: 50.

${ }^{12}$ Palaima, 2002: 210. «The Crock» conota o professor com a insensibilidade associada aos crocodilos, Patterson, 2009: 25.

${ }^{13}$ Os versos citados no quadro são os de $O d$. 1-5:

«Fala-me, Musa, do homem versátil que tanto vagueou, depois que de Tróia destruiu a cidadela sagrada.

De muitos homens viu as cidades e a mente conheceu;

e foram muitas no mar as dores que sofreu em seu coração para salvar a vida e o regresso dos companheiros.»

(trad. de F. Lourenço).

${ }^{14}$ Sobre esta questão, cf. Palaima, 2002: 210.

${ }^{15}$ Tal como acontece com Millie, a personagem de Peter Gilbert sofre uma mutação relativamente ao texto original e ao filme de 1951, passando a chamar-se "Tom Gilbert», no filme de 1994. Millie vem a chamar-se "Laura». As razões destas mudanças não são claras, mas talvez tenham que ver com o impacte dos nomes em causa nas respectivas épocas. «Tom», por exemplo, sugere uma forma onomástica mais informal do que «Peter»; já «Millie» será talvez agora um nome mais associado a classes menos «eruditas». 
então a ler a citação em grego, traduzindo-a depois: God from afar looks graciously upon a gentle master ("Ao que usa gentilmente o seu poder, um deus o contempla de longe com benevolência», trad. de M. O. Pulquério; no texto original, Rattigan usa a tradução que Herbert Weir Smyth fez para a colecção Loeb, em 1926 ${ }^{16}$ ). De novo, trata-se de um passo da peça de Ésquilo, os versos 950-953, correspondentes a uma fala do rei de Argos, que dirige estas palavras à mulher, Clitemnestra, para que a rainha receba hospitaleiramente a princesa troiana Cassandra, escrava de guerra, no palácio. Na peça de Rattigan, assim como nos filmes, os versos são transformados na epígrafe que Taplow escolhe como dedicatória ao seu professor de grego, que então se despede da escola. $\mathrm{O}$ passo é inclusive pretexto para a introdução de algumas referências técnicas, como a que, perante o embaraço e a surpresa do mestre relativamente à oferta, resulta da inquirição de Taplow sobre a acentuação de um dos versos do passo ( $\theta$ cò

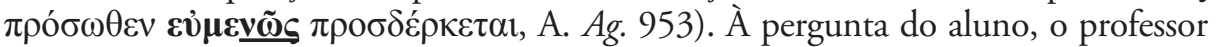
responde: "The perispomenon is perfectly correct.»

A preocupação de Crocker-Harris em frisar a escolha acertada do adjectivo gentle em vez de kind para traduzir o grego malthakos ( $\mu \alpha \lambda \theta \alpha \kappa \tilde{\omega} \varsigma$, A. Ag. 952) sugere o interesse em contrariar a alcunha "Hitler»" ${ }^{17}$ através da qual era troçado e alvo do sarcasmo dos estudantes da escola.

Ésquilo marca presença em duas outras cenas do filme de M. Figgis, sendo uma delas inédita relativamente ao texto original e à produção de 1951. Trata-se do momento em que, ao leccionar a última lição, Crocker-Harris pede a um dos alunos que leia um passo do Agamémnon esquiliano. O professor escolhe uma parte do monólogo que Clitemnestra profere depois de matar o marido e a concubina que com ele veio de Tróia (vv. 1372-1390). O rapaz lê a custo o texto grego, sem qualquer emoção, e o professor chama-lhe a atenção para a apatia, assumindo ele próprio a leitura, num modo particularmente enfático. A câmara foca Crocker-Harris quando ele começa a ler e a comentar a peça, mas, ao mesmo tempo que o entusiasmo e a paixão se apoderam do professor, a lente desvia o foco, concentrando-se então nos estudantes. A lente foca-se num em particular: John Taplow. Os miúdos assistem à declamação do professor, que parece saborear cada uma das palavras ditas pela rainha de Argos como se ele se identificasse com a vítima que Clitemnestra acaba de fazer com as próprias mãos. É nesse momento também que Taplow, um aluno que aparentemente apenas quer "despachar» as disciplinas de clássicas para passar para as de ciências no upper fifth, parece converter-se ao texto de Ésquilo, correndo o risco de se tornar um caso de êxito saído da turma de Crocker-Harris.

${ }^{16}$ Concomitantemente, na versão de 1994, nas cenas em que Crocker-Harris arruma os seus livros para abandonar a escola, vemo-lo guardar exemplares dessa mesma colecção Loeb, tanto os verdes (gregos) como os encarnados (latinos).

${ }^{17}$ Aqui é já usada a fórmula «Hitler». Vide nota 11. 
Como veremos, tanto o texto original como as adaptações de 1951 e de 1994 deixam espaço suficiente para que Taplow seja na verdade uma personagem ambígua, sem sabermos ao certo se a sua conversão às clássicas é um facto ou se uma mera estratégia para escapar ao «Himmler/Hitler do lower fifth» ${ }^{18}$. Mas o afecto que o aluno passa a nutrir pelo professor de literatura grega parece ser genuíno. Com efeito, é através de Ésquilo que Taplow percebe o poder e o fascínio da literatura, sem que isso, no entanto, anule o seu interesse e gosto pelas ciências experimentais.

A outra cena em que o texto grego é fulcral é comum ao texto original de Rattigan e às adaptações de Asquith e de Figgis. Trata-se da aula privada de Taplow, que decorre no apartamento do professor (no jardim, no caso da adaptação de 1994). Apesar de ser o seu último dia de trabalho, Crocker-Harris faz questão de honrar o compromisso que tem com o pai de John Taplow e de ministrar ao aluno a última sessão de tutoria. A aula centra-se de novo no Agamémnon de Ésquilo e o mestre põe o discípulo a traduzir os versos 1399-1400 da peça: «Admiramos a tua língua, a audácia das palavras com que te jactas em relação a teu marido» (trad. de M. O. Pulquério).

Esta é uma fala do corifeu que se segue imediatamente ao monólogo de Clitemnestra interpretado por Crocker-Harris na cena anteriormente mencionada. Taplow (Brian Smith, na versão de 1951) faz o que os Ingleses designam por construe, i.e., traduz literalmente o texto, através de uma análise gramatical de base. O professor corrige o aluno a cada passo, até ao momento em que o rapaz decide propor uma tradução mais livre e bem menos literal da que o exercício exige.

Calmamente, Crocker-Harris reage, introduzindo ironia ao episódio: «Taplow, I presume you are using a different text from mine... Why do you invent words that simple are not there? ${ }^{19} \mathrm{~A}$ resposta do aluno corresponde à ideia de que o tradutor deve ter alguma liberdade quando verte para uma língua vernácula um texto clássico. Na verdade, Taplow faz um autêntico exercício de hermenêutica, de exegese da tradução e as suas palavras mostram que o rapaz assimilou a essência da literatura ao apropriar-se do texto e ao transformá-lo em algo também seu. A reacção do professor, porém, traduz a rigidez dos parâmetros por que ele se rege e que, de algum modo, o levaram ao conflito interior em que se encontra e que se revela num misto de frustração e desencanto. Taplow, contudo, descobre que há mais num texto de Ésquilo do que um mero exercício de construing ou de análises sintácticas e morfológicas ${ }^{20}$. Há também espírito, ideia, filosofia e arte. É o próprio rapaz que o revela ao professor quando propõe e justifica a sua tradução livre do passo do Agamémnon. $\mathrm{O}$ que Crocker-Harris parece não compreender é que ele próprio contribuiu e foi

\footnotetext{
${ }^{18}$ Vide Patterson, 2009: 17-18.

${ }^{19}$ Sobre este diálogo, vide Coelho, 2009.

${ }^{20}$ Sobre a problemática da tradução, vide e.g. Sousa, 1994; Aguilar Miquel, 2015.
} 
essencial para a descoberta de Taplow. Quanto ao espectador, este percebe-o quando, a determinado momento, mestre e discípulo discorrem, ou discutem mesmo, sobre a tragédia de Ésquilo como pares. Apesar do «espírito científico» de Taplow, o rapaz pode afinal ser o tal caso de sucesso em mil, de que Crocker-Harris fala a Gilbert (Ronald Howard, na versão de 1951) no início da narrativa.

A presença dos clássicos em geral e de Ésquilo em particular em The Browning Version não se limita, porém, a referências explícitas. Parece-nos, por exemplo, serem possíveis leituras mais ou menos metafóricas da tragédia esquiliana e do mito a ela associado. Assim, há uma correlação entre a personagem "Millie/Laura»" e Clitemnestra. Essa associação faz-se através do carácter amargurado e ressentido de Mrs. Crocker-Harris, talvez mais claro na interpretação de Jean Kent, no filme de A. Asquith, do que na de Greta Scacchi na versão de M. Figgis, e também, de modo subliminar, por meio do passo escrito no quadro negro (vv. 414-419), na versão de 1951; ou ainda através da explicação que, no filme de 1994, Crocker-Harris dá aos estudantes para o monólogo de Clitemnestra (vv. 1372-1390), a quem descreve como «uma mulher que destruiu o seu marido». O mestre considera a possibilidade de Ésquilo não ter conhecido de facto nenhuma mulher como essa, mas frisa que o poeta teria por certo conhecimento da existência desse tipo de mulheres, como que evocando a sua própria esposa. Quando descreve a heroína trágica como «cruel», «orgulhosa», "triunfante»e até mesmo «desafiante», ele está ao mesmo tempo a dar uma antevisão do que reconheceremos na própria Mrs. Crocker-Harris. O mesmo é perceptível pela forma cínica, amarga e até cruel como ela sugere ao marido que o presente de Taplow não deverá passar de um mero suborno para atenuar o facto de o rapaz ter sido apanhado a imitar o professor, cena fundamental na economia do enredo e por isso presente em todas as versōes do texto de Rattigan.

Esta insinuação, com que Mrs. Crocker-Harris destila emoções que oscilam entre o ódio, o desprezo e a pena, equivale a uma execução metafórica do marido, tornando-a um alter ego da Clitemnestra de Ésquilo. Com efeito, tal como a heroína grega, a mulher deste professor pode ser uma senhora de uma "máscula vontade», que destrói o marido não com redes e machados, mas com palavras que podem ser tão cruéis como lâminas ${ }^{22}$.

Por sua vez, Andrew Crocker-Harris funciona como uma leitura da figura de Agamémnon, o homem que combateu por uma causa e acabou por abandonar a mulher na sua casa, abrindo espaço para a intrusão de um terceiro elemento. No mito grego, o intruso é Egisto. Na peça de Rattigan e nos filmes que a adaptaram,

${ }^{21}$ Vide nota 15.

${ }^{22}$ A este propósito, vide Rodrigues, 2010. Para uma comparação sistemática destas figuras, vide Coelho, 2009; Bertolini, 2016: 111. Talvez a Millie de Kent seja uma mulher mais detentora de máscula vontade do que a Laura de Scacchi. Mas ambas as personagens exibem uma garra que o marido parece não ter. 
é Frank Hunter (Nigel Patrick em 1951/Matthew Modine em 1994), o professor de ciências. A dialéctica entre os dois homens estabelece-se a vários níveis e acarreta várias implicaçōes. Frank é jovem, atlético, detentor de um espírito científico, no sentido comum do termo. A versão de $\mathrm{M}$. Figgis transformou-o num americano deslumbrado com a história do lugar, evocando uma sociedade progressista e moderna. A forma de falar deste Frank Hunter tem inclusive de ser corrigida pela própria amante dele, que lhe chama a atenção para o facto de, em inglês correcto, i.e. britânico, se dizer of whom e não of who. Hunter é sinónimo de mudança, de evolução.

Andrew, em contrapartida, é um homem de meia-idade, sedentário, um scholar que o espírito popular (e até algum elitismo, ignorante da epistemologia do racionalismo crítico de Karl Popper) não entende como cientista. Andrew identifica-se com a sociedade tradicional inglesa, em franco processo de decadência. As versōes fílmicas contrastam-no também com o bem-sucedido e popular instrutor de cricket, Mr. Fletcher (Bill Travers em 1951/David Lever em 1994). Ainda assim, como bom classicista que é, o Andrew Crocker-Harris de 1994 sabe apreciar o desporto. Esta adaptação apresenta-o como alguém ultrapassado, que deve por isso ser afastado (omitindo-se qualquer referência à doença cardíaca mencionada no texto original de Rattigan), em nome de uma modernização da escola e dos curricula $^{23}$. Recordese que, nesta adaptação, Gilbert vem implementar sobretudo o ensino das línguas modernas, como o francês, o alemão e o espanhol. Crocker-Harris suspeita mesmo de que o grego e o latim venham a ser eliminados do curriculum, em nome de uma sociedade moderna e intercultural, ainda que volúvel a modas, mas na qual parece não haver lugar para saberes sem uma aplicação prática imediata ou evidente ao sensocomum, como parecem ser as línguas clássicas para quem não está preparado para ela $^{24}$. Com efeito, a personagem não teria o mesmo impacte e significado se fosse identificada como um professor de genética ou de robótica ${ }^{25}$. Por sua vez, na conversa que mantém com Gilbert e o director da escola (Dr. Frobisher, Wilfrid Hyde-White em 1951 / Michael Gambon em 1994), Frank Hunter traduz uma percepção popularizada, superficial e pouco profunda da cultura clássica, ao aludir a ela como uma fonte de perversões que, longe da inocência dos odores dos seus reagentes químicos, tratam de estupros, assassínios e incestos (na versão de 1951, a referência é ainda mais erudita, visto que Gilbert se refere às perversōes que constam da Antologia Grega, colectânea que reúne vários poemas sobre homoerotismo e homossexualismo, por exemplo ${ }^{26}$ ).

${ }^{23}$ Sobre esta problemática, vide Ferreira, 2017, e bibliografia aí indicada.

${ }^{24}$ Crocker-Harris ironiza mesmo com o interesse dos Ingleses em aprender russo até ao processo perestroika. Esta foi uma moda que depois se desvaneceu. A presença dos alunos africanos na escola traduz a multiculturalidade contemporânea.

${ }^{25}$ Note-se como, na versão de Figgis, um dos governors da escola, Lord Baxter, é alguém ligado às tecnologias de ponta e não um general aposentado, como acontece na adaptação de Asquith.

${ }^{26}$ Aqui, deverá ser tida em conta a questão da sexualidade em Rattigan e as possíveis implicaçôes desta insinuação à luz dessa problemática. $\mathrm{O}$ mesmo deve ser considerado para uma análise do momento em que Crocker-Harris alude ao desconhecimento que teria dos «factos da vida», quando 
Esta perspectiva corresponde, parece-nos, a uma agenda ideológica tecnocrática e a um entendimento da cultura clássica como algo obsoleto e ultrapassado, por oposição às ciências experimentais e à tecnologia e que esteve muito em voga na Europa do pós-guerra, em meados e finais do século XX (e de certo modo vigora ainda em alguns sectores sócio-culturais como reminiscência dessa tendência), quando o desenvolvimento económico era justificação para quase tudo, como se houvesse uma hierarquia de saberes. Talvez por isso mesmo a adaptação cinematográfica de 1994 seja mais focada nesta problemática do que a de $1951^{27}$. Mas a nossa herança patrimonial e o nosso $\mathrm{ADN}$ cultural não caducam e, sejamos nós conscientes deles ou não, mantêm-se e persistem.

Neste contexto, Millie/Laura, outrora conquistada pelo recém-formado jovem oxoniense, é agora uma mulher desiludida. Os seus sentidos são atraídos pela juventude de Frank Hunter, sendo inevitável uma leitura erotizada dessa atracção. Millie/Laura surge como uma mulher de carnalidade, por oposição a Andrew, que parece ser um homem essencialmente cerebral, pelo menos no que à mulher diz respeito $^{28}$. A hybris que faz dele um herói de contornos trágicos, aliás bem próximo de Willy Loman, o desiludido caixeiro-viajante de A. Miller, está em ter-se casado com uma mulher que é o oposto absoluto de si mesmo ${ }^{29}$. A infelicidade e a desilusão abateram-se sobre ambos, como consequência dessa hybris, sendo deste modo permitido ao espectador criar alguma empatia com aquela mulher, tal como pode criar com a Clitemnestra de Ésquilo, pois sabe que por detrás da violência do seu acto está o desejo de vingança de uma mãe pela morte da sua filha, Ifigénia.

Esta leitura parece ir ao encontro de outra linha clássica de interpretação, assente no que podemos ler no Banquete de Platão e nas formas de amor e de amar que aí se teorizam ${ }^{30}$. Aliás, Platão não terá sido estranho à composição de

se casou com Millie. Com efeito, a forma como Rattigan aborda a problemática da sexualidade nos seus textos dá a entender a importância que o tema da homossexualidade deveria ter para ele (muito provavelmente, por ser homossexual). A peça The Deep Blue Sea (1952), por exemplo, foca uma relação adúltera heterosexual que, no entanto, foi entendida como uma metáfora de uma relação homossexual do próprio dramaturgo. A este propósito, escreve Patterson, 2009: 32, "Certainly the kind of pain embodied in Andrew and Millie can be related to the pain experienced by a gay man living in England in the mid-twentieth century when homosexuality was a crime and someone like John Gielgud could be arrested. Rattigan has been faulted by some for rewriting roles in plays to change a character from homosexual to heterosexual in order to make the play more acceptable, but the discrepancy between private passion and public persona is not limited to a gay sensibility.»

${ }^{27}$ Patterson, 2009: 108.

${ }^{28}$ Vide nota 26.

${ }^{29}$ Patterson, 2009: 29. Na versão de 1994, Crocker-Harris diz a Hunter que o seu casamento é digno de Fausto. Trata-se de outra referência erudita, mas repleta de sentido, pois, tal como Fausto ama Margarida e pensa que ela pode ser a salvação dele, a verdade é que o seu destino é outro, por estar comprometido com Mefistófeles.

${ }^{30}$ Vide nota 26 e Patterson, 2009: 29, que leva esta leitura mais longe, implicando mesmo a sexualidade latente às personagens. 
Andrew Crocker-Harris, ou haverá dúvidas de que a cena da despedida do professor perante a escola (ausente da peça, mas integrada em ambos os filmes) é fundamentalmente uma apologia, com a qual ele começa por defender os valores clássicos associados à filosofia, à política, à justiça, à arte e às línguas, e acaba a justificar-se, a si mesmo e ao seu fracasso? 31

Por essa razão, também, e por ser um homem íntegro que assume as suas responsabilidades perante o que é definido como «soul-destroying lower fifth», Crocker-Harris entricheirou-se numa fortaleza, dentro de si mesmo, simbolicamente representada pelos seus aposentos. $\mathrm{Na}$ falta de afecto humano, este homem refugiou-se no amor que tinha pelos clássicos, dando corpo e pertinência ao aforismo de F. Nietzsche: Wir haben die Kunst, damit wir nicht an der Wahrheit zu Grunde gehen (Nós temos a arte para que não sucumbamos à verdade.) ${ }^{32}$

Neste sentido, o próprio Andrew Crocker-Harris é metáfora de mais um tema clássico: o da cidade de Tróia fortificada (note-se como o tema de Tróia é recorrente nas citações do grego no filme), na qual o inimigo não entra até ao estratagema do cavalo. Em The Browning Version, o jovem Taplow é esse invasor e a tradução de Robert Browning, o seu cavalo de madeira ${ }^{33}$.

Perante uma turma desapontada com os comentários que o professor faz aos resultados dos exercícios de latim e a necessidade que sente em condenar o exibicionismo excessivo do professor de ciências, Crocker-Harris adapta o conhecido aforismo latino Ars est celare artem (A arte está em dissimular o artifício), proferindo Scientia est celare scientiam (A ciência está em dissimular o que se sabe). Este momento, que espoleta em Taplow uma reacção de simpatia para com o professor, associado àquele em que Crocker-Harris revela (transgredindo as suas próprias regras) em latim ao aluno que passou a clássicas e que prosseguirá para o upper fifth é, parece-nos, um excelente indicador da essência do carácter desta personagem. A sua vida resumese ao amor pelo ensino e pela cultura clássica que tanto quis transmitir aos seus alunos. Como ele próprio afirma, quanto a esse processo, em mil casos, terá falhado 999. $\mathrm{O}$ seu desaire acentua-se com o fracasso da vida amorosa. Mas dificilmente alguém poderia acusar Crocker-Harris, um homem preso no seu quotidiano e, por isso, herói trágico contemporâneo, de não ter tentado viver e fazer valer aquilo em que acreditava, em prol das suas convicções e da formação dos outros como cidadãos de uma politeia de valores humanísticos, i.e. clássicos.

A proposta que apresentámos para analisar as várias versões de The Browning Version permite-nos, também, confirmar a perenidade dos temas da Antiguidade Clássica, não só no teatro e no cinema, como também nas pertinentes e necessárias reflexōes que devemos fazer sobre a forma como os transmitimos, designadamente em sala de aula.

\footnotetext{
${ }^{31}$ Patterson, 2009: 107-108.

${ }^{32}$ F. Nietzsche, Nachgelassene Fragmente 1887-1889, 16 (49).

${ }^{33}$ Esta ideia é já sugerida por Patterson, 2009: 21.
} 


\section{REFERÉNCIAS BIBLIOGRÁFICAS}

Aguilar MiQUel, J. (2015): «La traducción pedagógica como herramienta didáctica: hacia una nueva propuesta de aplicación en el aula», Thamyris 6: 137-165.

Benardete, S. (1997): The Bow and the Lyre. A Platonic Reading of the Odyssey, Rowman \& Littlefield Publishers, Lanham.

BerTOlini, J. A. (2016): «The Browning Version: Words could so lacerate a man's heart», in The Case for Terence Rattigan, Playwright, Palgrave MacMillan, Middlebury, pp. 101-112.

Coelho, M. C. M. N. (2009): «A recepção de Agamêmnon nas terras da Rainha. As versōes de Browning, Rattigan, Asquith e Figgis», Aletria 19 (n.e.): 163-176.

FERreirA, F. (2017): «Ensinar e aprender Latim no século XXI», BEC 62: 125-137.

FoX, R. L. (2010): «Alexander on Stage: A Critical Appraisal of Rattigan's Adventure Story», in P. CARTLEDGE \& F. R. Greenland (eds.), Responses to Oliver Stone's Alexander. Film, History, and Social Studies, The University of Wisconsin Press, Madison, pp. 55-91.

LourençO, F. (2018): Homero. Odisseia, Quetzal Editores, Lisboa.

Martínez Hernández, M. (2012): «La literatura griega antigua en el cine», in G. Santana HenríQUEZ (ed.), Literatura y Cine, Ediciones Clásicas, Madrid, pp. 11-65.

Palaima, T. G. (2002): "The Browning Version's and Classical Greek. "TAPLOW. It's for you, Sir"», in B. AMDEN et al., Noctes Atticae. 34 Articles on Graeco-Roman Antiquity and its Nachleben. Studies presented to Jorgen Mejer on his Sixtieth Birthday March 18, 2002, Museum Tusculanum Press, University of Copenhagen, Copenhagen, pp. 199-214.

Patterson, R. G. (2009): Two Movies. Where they came from, How they work and What they mean, RGP, Los Angeles.

Pulquério, M. O. (1992): Ésquilo. Oresteia-Agamémnon, Coéforas, Euménides, Ediçōes 70, Lisboa.

Rattigan, T. (1955): The Deep Blue Sea, with three other plays: Harlequinade. Adventure story (and) The Browning version, Pan Books, London.

RatTigan, T. (1994): The Browning Version, Nick Hern Books, London.

Rocha Pereira, M. H. (1996): Eurípides. As Troianas, Edições 70, Lisboa.

Rodrigues, N. S. (2001): «Garrett e a tragédia de tema clássico. O exemplo de Mérope», Humanitas 53: 385-408.

Rodrigues, N. S. (2010): «Ainda Clitemnestra, a "mulher de máscula vontade” ", Cadmo 20: 393-405.

Solomon, J. (2001): The Ancient World in the Cinema, Yale University Press, New Haven.

SousA, A. A. A. (1994): «Do Latim ao Português: breve abordagem da problemática da tradução», Clássica 20: 343-349.

Sousa e Silva, M. F. (2005): Ésquilo, o Primeiro Dramaturgo Europeu, Imprensa da Universidade de Coimbra, Coimbra. 